\title{
The nanometer magnetic solid base catalyst for production of biodiesel
}

\author{
Chang Liu ${ }^{\mathrm{a}, \mathrm{b}}$, Pengmei Lv ${ }^{\mathrm{a}, *}$, Zhenhong Yuan ${ }^{\mathrm{a}}$, Fang Yan ${ }^{\mathrm{a}}$, Wen Luo ${ }^{\mathrm{a}}$ \\ ${ }^{a}$ Guangzhou Institute of Energy Conversion, Chinese Academy of Sciences, Key Laboratory of Renewable Energy and Gas Hydrate, CAS, No.2 Nengyuan Rd., Wushan, Tianhe, \\ Guangzhou, Guangdong 510640, PR China \\ ${ }^{\mathrm{b}}$ Graduate School of Chinese Academy of Sciences, Beijing 100039, PR China
}

\section{A R T I C L E I N F O}

\section{Article history:}

Received 1 June 2009

Accepted 10 October 2009

Available online 3 November 2009

\section{Keywords:}

Biodiesel

Transesterification

Nanometer

Magnetic

Solid base

New crystalloid

\begin{abstract}
A B S T R A C T
Nanometer magnetic solid base catalysts were prepared by loading $\mathrm{CaO}$ on $\mathrm{Fe}_{3} \mathrm{O}_{4}$ with $\mathrm{Na}_{2} \mathrm{CO}_{3}$ and $\mathrm{NaOH}$ as precipitator, respectively. The optimum conditions for preparation of this catalyst were investigated. The influence of the proportion of $\mathrm{Ca}^{2+}$ to $\mathrm{Fe}_{3} \mathrm{O}_{4}$ on the catalytic performance has been studied. The catalyst with highest catalytic activity has been obtained when the proportion of $\mathrm{Ca}^{2+}$ to $\mathrm{Fe}_{3} \mathrm{O}_{4}$ is $7: 1$; the catalytic activity of the catalyst calcined from $\mathrm{Ca}(\mathrm{OH})_{2}$ to $\mathrm{Fe}_{3} \mathrm{O}_{4}$ is better than that calcined from $\mathrm{CaCO}_{3}$ to $\mathrm{Fe}_{3} \mathrm{O}_{4}$; under the conditions of methanol/oil molar ratio of $15: 1$, catalyst dosage of $2 \mathrm{wt} \%$ and temperature of $70^{\circ} \mathrm{C}$, the biodiesel yield reaches to $95 \%$ in $80 \mathrm{~min}$, even to $99 \%$ finally. The catalytic activity and recovery rate of the nanometer magnetic solid base catalysts are much better than those of $\mathrm{CaO}$. Calcination temperature was determined by differential thermogravimetric analysis. $\mathrm{Ca}_{2} \mathrm{Fe}_{2} \mathrm{O}_{5}$, a kind of new metal multiple oxide, was found in the catalyst through X-ray diffraction. At the end, these catalysts were characterized by scanning electronic microscope (SEM), transmission electron microscopy (TEM), and vibrating sample magnetometer (VSM).
\end{abstract}

(c) 2009 Elsevier Ltd. All rights reserved.

\section{Introduction}

Biodiesel can be considered as an environmental friendly energy source. With regard to the emissions, it has been demonstrated that its net $\mathrm{CO}_{2}$ emission is rather low taking into account its renewable origin. Other toxic emissions like $\mathrm{CO}, \mathrm{SO}_{x}$, unburned hydrocarbons and soot particles are also considerably reduced when burnt in the Diesel engine (the results concerning the $\mathrm{NO}_{x}$ emission indicates slightly higher values than conventional diesel).[1] Meanwhile, its lubricant property can prolong the engine's life. Other advantages of the biodiesel are high cetane number, high flash point and acceptable cold filter plugging point (CFPP), which makes it very attractive as an alternative fuel.[2] Therefore, biodiesel seems like one of the best successor of fossil fuel.

Basic homogeneous catalysts are applied in the transesterification reaction for traditional biodiesel production. And they have high catalytic activity because of the multiple contact between reagents and catalysts. Freedman et al. [3] reported that $\mathrm{NaOH}$ can transform vegetable oil to biodiesel completely in an hour. But their disadvantages are the complicated process of post treatments and pollution. The advantages of basic solid catalysts are easy separation and simple post treatments. Nevertheless, the

\footnotetext{
* Corresponding author. Tel.: +86 20 87057760; fax: +86 2087057737.

E-mail address: lvpm@ms.giec.ac.cn (P. Lv).
}

specific surface area of these kinds of catalysts is too small to contact reagents abundantly and reduce biodiesel conversion. Nanometer magnetic basic solid catalyst combines the merit of basic homogeneous catalysts - the huge specific surface area, and the merit of basic solid catalysts - separated easily from the reagents. Therefore, Nanometer magnetic basic solid catalyst can reduce the costs and protect the environment.

Nowadays, solid base catalysts for transesterification become a focus of research. Mazzochia et al. [4] found that though $\mathrm{Ba}(\mathrm{OH})_{2}$ had a high catalytic activity, there were $0.06 \%$ and $0.25 \% \mathrm{Ba}(\mathrm{OH})_{2}$ remaining in the resulting fatty acid methyl esters (FAME) and glycerin, respectively. Thereby, Ba $(\mathrm{OH})_{2}$ is not a completely heterogeneous catalyst. Yang and Xie [5] catalyzed transesterification reaction using $\mathrm{ZnO}$ loaded $\mathrm{Sr}\left(\mathrm{NO}_{3}\right)_{2}$ at $873 \mathrm{~K}$ for $5 \mathrm{~h}$. The rate of FAME yield is $94.5 \%$ at reflux of methanol $\left(65^{\circ} \mathrm{C}\right)$, with a 12:1 molar ratio of methanol to soybean oil and a catalyst amount of $5 \mathrm{wt} \%$. However, the used catalyst is significantly deactivated and cannot be directly reused for transesterification. Leclercq et al. [6] tested the catalytic activity of commercial $\mathrm{MgO} / \mathrm{Al}_{2} \mathrm{O}_{3}$ hydrotalcites and $\mathrm{MgO}\left(300 \mathrm{~m}^{2} / \mathrm{g}\right)$ in the transesterification of rapeseed oil. The result shows that $\mathrm{MgO}$ is more active than hydrotalcites. Some other research illustrates that $\mathrm{MgO}$ and hydrotalcites still has high activity even the water content is $10000 \mathrm{ppm}$ at $180^{\circ} \mathrm{C}$, which is of great significance for decreasing pretreatment costs [7]. Nevertheless, Oku et al. [8] confirmed that $\mathrm{MgO}$ and calcined hydrotalcites were soluble in the resulting FAME, and the relict mass 
concentration of $\mathrm{Mg}$ and $\mathrm{Al}$ was $17800 \mathrm{ppm}$ and $6900 \mathrm{ppm}$, respectively. Hence, it cannot be the catalyst for industrial biodiesel production. Corma et al. [9] reported that calcined Li/Al hydrotalcites was more active for the transesterification than the $\mathrm{Mg} / \mathrm{Al}$ material (or $\mathrm{MgO}$ ) due to their higher Lewis basicity. Based on the result of Corma, Shumaker et al. [10] studied calcined Li/Al layered double hydroxide as a catalyst for the conversion of soybean oil to FAME. High FAME yield was achieved at the evaporation temperature of methanol and low catalyst load (2-3 wt\%) and short reaction time $(\sim 2 \mathrm{~h})$. Furthermore, the catalyst still has high catalytic activity after 3-times using, yet a little Li element filters out from the catalyst. Some literatures have also reported that the sodium [11] or potassium [12-14], as well as $\mathrm{MgO}$ or $\mathrm{Al}_{2} \mathrm{O}_{3}$ supported $\mathrm{K}_{2} \mathrm{CO}_{3}$, exhibited high catalytic activities for the transesterification reaction at the temperature of $60-63^{\circ} \mathrm{C}$, when they were prepared by loading on a support(normally alumina) using several precursors and calcined at $500-600{ }^{\circ} \mathrm{C}$. But $\mathrm{K}_{2} \mathrm{CO}_{3}$ was found dissolved into the solution [15].

$\mathrm{CaO}$ as a transesterification catalyst has been proved to be effective. Nevertheless, when $\mathrm{CaO}$ catalyzes the transesterification reaction directly, the lattice oxygen species on the surface would form hydrogen bonds with methanol or glycerin easily, which increases the viscosity of glycerin and forms suspensoid with $\mathrm{CaO}$. As a result, $\mathrm{CaO}$ catalyst, as well as glycerin, is difficult to be separated. It complicates the post treatments, even pollutes the environment and increases the costs. [16] However, $\mathrm{CaO}$ anchored on supporters can solve the issue. Furthermore, the importance of supporters of catalysts and the percentage of $\mathrm{CaO}$ can be observed from the results of Monica C.G. Albuquerque et al.'s [17] research. The catalysts of $\mathrm{CaO}$ loaded on different supports with different weight percentage have been tested about their catalytic activity.

The nanometer magnetic catalyst which is prepared by loading $\mathrm{CaO}$ onto the nanometer $\mathrm{Fe}_{3} \mathrm{O}_{4}$ could improve the catalytic performance. This catalyst can connect reagents sufficiently and be separated easily by exerting magnetic field after transesterification reaction. That can simplify the process and decrease costs. A series of experiments were conducted to improve this kind of catalyst by changing the molar percentage of $\mathrm{CaO}$.

\section{Materials and methods}

\subsection{Materials}

The materials include Jatropha curcas oil, analytically pure agents of anhydrous calcium chloride, sodium hydroxide, sodium carbonate, ferric sulfate, ferrous sulfate, ammonia et al.

\subsection{Methods of magnetic core preparation}

$\mathrm{FeSO}_{4} \cdot 7 \mathrm{H}_{2} \mathrm{O}$ and $\mathrm{Fe}_{2}\left(\mathrm{SO}_{4}\right)_{3} \cdot 7 \mathrm{H}_{2} \mathrm{O}$ were dissolved in the distilled water with the proportion of $1: 2$, and $20 \%$ ammonia was dropped into the solution with drastic stirring. After aging for $1 \mathrm{~h}$, black precipitates were formed, and $\mathrm{SO}_{4}^{2-}$ was eliminated by washing many times.

\subsection{Preparation of nanometer magnetic solid base catalyst}

Some $\mathrm{CaCl}_{2}$ was solved into distilled water, then a certain amount (the proportion of $\mathrm{Ca}^{2+}$ to $\mathrm{Fe}^{2+}+\mathrm{Fe}^{3+}$ was controlled to be 10:1) of magnetic core was added into the $\mathrm{CaCl}_{2}$ solution. The solution of $\mathrm{NaOH}$ was titrated into the solution under vigorous stirring and aged for $18 \mathrm{~h}$ at $65^{\circ} \mathrm{C}$, then the magnetic material was precipitated by placing at 2200 Gauss magnetic field from permanent magnet $\mathrm{NeFeB}$. The magnetic material was washed over and over again until its $\mathrm{pH}$ value came to 7 and then dried for $12 \mathrm{~h}$ in a vacuum at $80^{\circ} \mathrm{C}$. Finally, the sample was calcined for $8 \mathrm{~h}$ at $800^{\circ} \mathrm{C}$ to transform to multiple oxides to achieve nanometer magnetic solid base catalyst.

The catalysts with different proportions (5:1 and 7:1) of $\mathrm{Ca}^{2+}$ to $\mathrm{Fe}_{3} \mathrm{O}_{4}$ were prepared with the same method. Meanwhile, the catalysts with different proportions of $\mathrm{Ca}^{2+}$ to $\mathrm{Fe}_{3} \mathrm{O}_{4}$, i.e. 5:1, 7:1 and $10: 1$, were made respectively with the precipitator being $\mathrm{Na}_{2} \mathrm{CO}_{3}$.

In order to compare the catalytic activity of the nanometer magnetic solid base catalyst with that of pure $\mathrm{CaO}$, the $\mathrm{CaO}$ catalyst was prepared in the same way with the precipitators being $\mathrm{NaOH}$ and $\mathrm{Na}_{2} \mathrm{CO}_{3}$.

\subsection{Methods of catalysts characterization and activity detection}

TENSOR27 from BRUKER (Germany) Company was used for TGDTA analysis in a nitrogen atmosphere at $5{ }^{\circ} \mathrm{C} / \mathrm{min}$ heating rate; The specific surface area was obtained by Coulter (SA3100) at $150^{\circ} \mathrm{C}$ deaeration temperature for $3 \mathrm{~h}$ deaeration time; Xportpro from Panalytical Company was used for X-ray diffraction; SEM photograph was taken by Quanta 400 thermal field from Philips FEI company and TEM picture was attained by FEI-Tecnai 12; Magnetic strengths of samples were detected by Lakeshore7410 VSM; The rates of transesterification were monitored by SHIMAZU GC2100, and the condition was as below: in a nitrogen atmosphere, the split ratio was 30 , the inject temperature was $210^{\circ} \mathrm{C}$, and the detector temperature was $195^{\circ} \mathrm{C}$.

\section{Results and discussion}

\subsection{Catalytic activities of magnetic solid base catalysts}

\subsubsection{The optimization of catalyst preparation}

To explore the effect between the activity of catalyst and the load amount of $\mathrm{CaO}$, all of the catalysts activities were tested under the same conditions of methanol/oil molar ratio of 15:1, catalyst dosage of $2 \mathrm{wt} \%$ and temperature of $70^{\circ} \mathrm{C} .120 \mathrm{ml}$ Jatropha curcas oil and $73.5 \mathrm{ml}$ methanol were put into three-necked flask and reacted for $4 \mathrm{~h}$ and were sampled every half an hour. The results are shown in Fig. 1.

Fig. 1 indicates that the catalytic activity of pure $\mathrm{CaO}$ is less than that of other catalysts. Catalyzed by $\mathrm{CaO}$, the conversion of oil to esters cannot reach $80 \%$, while for magnetic catalyst, the conversion rate reaches more than $80 \%$, especially the $\mathrm{Ca}(\mathrm{OH})_{2} 7$ (These catalysts are named with their precursors and the proportion of $\mathrm{Ca}^{2+}$ to $\mathrm{Fe}_{3} \mathrm{O}_{4}$ for short. For example, " $\mathrm{Ca}(\mathrm{OH})_{2} 10$ "means that the precursor of the

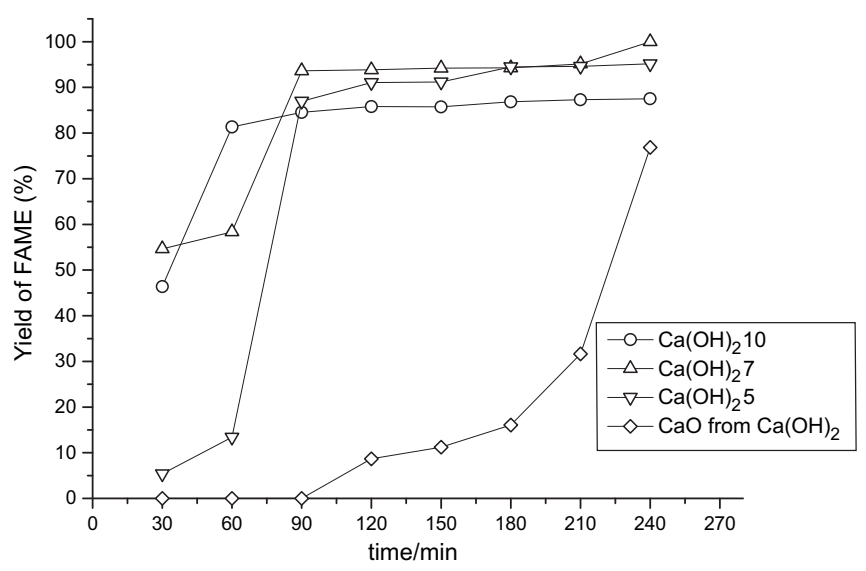

Fig. 1. Influence of different $\mathrm{CaO}$ load on catalytic performance for transesterification reaction. 
catalyst is $\mathrm{Ca}(\mathrm{OH})_{2}-\mathrm{Fe}_{3} \mathrm{O}_{4}$ and the proportion of $\mathrm{Ca}^{2+}$ to $\mathrm{Fe}_{3} \mathrm{O}_{4}$ is $10: 1$ ) reaching $99 \%$ after $4 \mathrm{~h}$ reaction. It has been proved by other researchers that pure $\mathrm{CaO}$ catalyst shows a lower catalytic activity in normal surroundings. For instance, in Arzamendi et al's. [18] study, catalyzed by $\mathrm{CaO}$ (Aldrich, 99.9\%) for the transesterification of oil, the conversion is below 20\% in $5 \mathrm{~h}$ and below $90 \%$ in $10 \mathrm{~h}$. Masato Kouzu et al. [19] reported that the conversion of transesterification reaction can reach 93\% when $\mathrm{CaO}$ catalyzed $1 \mathrm{~h}$ in the nitrogen atmosphere. However, the conversion cannot achieve $10 \%$ after $4 \mathrm{~h}$ reaction when the transesterification reaction was catalyzed by $\mathrm{CaO}$ calcined in air. Moreover, using nanocrystalline calcium oxides can enhance the catalytic activity of $\mathrm{CaO}$. The nanocrystalline calcium oxides (crystal size $=20 \mathrm{~nm}$; specific surface area $=90 \mathrm{~m}^{2} / \mathrm{g}$ ) obtain $100 \%$ conversion of soybean oil at room temperature after $12 \mathrm{~h}$ while the conversion obtained by commercial $\mathrm{CaO}$ (crystal size $=43 \mathrm{~nm}$; specific surface area $=1 \mathrm{~m}^{2} / \mathrm{g}$ ) is only $2 \%$ [20]. Nevertheless, CaO loaded on $\mathrm{Fe}_{3} \mathrm{O}_{4}$ catalyzes the transesterification reaction very quickly and the conversion of the transesterification reaction is over $80 \%$ in $80 \mathrm{~min}$. It is possibly because that a new kind of multiple oxide with higher catalytic activity for the transesterification reaction than $\mathrm{CaO}$ is formed during calcination. Meanwhile, for the transesterification reaction catalyzed by $\mathrm{CaO}$ loaded on $\mathrm{MgO}$, the conversion can reach $92 \%$ under the conditions of methanol/oil molar ratio of $18: 1$, the catalyst dosage of $2 \mathrm{wt} \%$ of oil, and temperature of $64.5^{\circ} \mathrm{C}$ in $3.5 \mathrm{~h} \mathrm{[21].} \mathrm{Ca}(\mathrm{OH})_{2} 7$ is outstanding probably due to the compatible proportion of $\mathrm{Ca}^{2+}$ to $\mathrm{Fe}_{3} \mathrm{O}_{4}$. On one hand, if the proportion of $\mathrm{Ca}^{2+}$ is too big, redundant $\mathrm{CaO}$ may accumulates on the surface of $\mathrm{CaO}-\mathrm{Fe}_{3} \mathrm{O}_{4}$ and prevents the contact between the activity sites and the reactant; on the other hand, if the proportion of $\mathrm{Ca}^{2+}$ is too small, less active multiple oxides, as well as basic active sites, are formed than that of $\mathrm{Ca}(\mathrm{OH})_{2} 7$. Therefore, there exists an optimum $\mathrm{CaO}$ proportion.

\section{A}

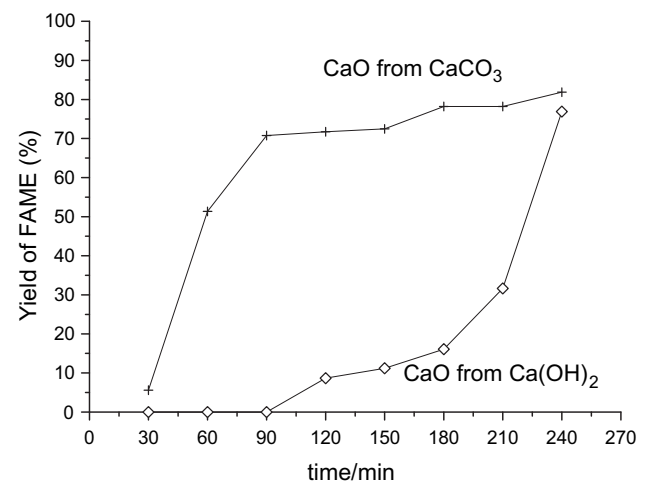

C

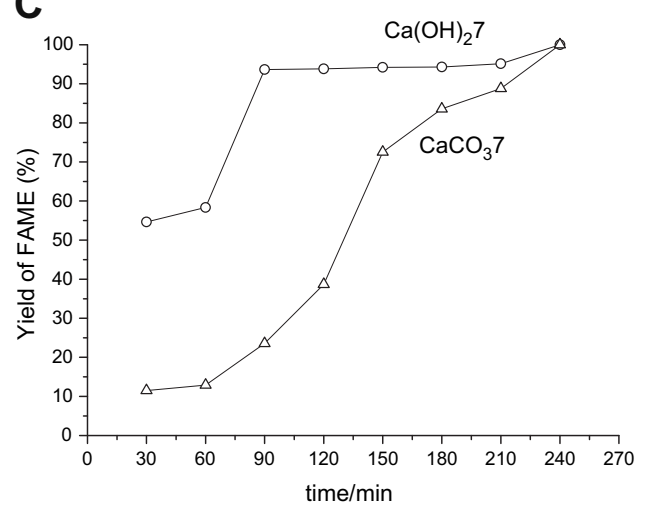

In order to reveal the effect of the precipitator on the catalytic activity, the catalysts precipitated by $\mathrm{NaOH}$ and $\mathrm{Na}_{2} \mathrm{CO}_{3}$ were compared. Fig. 2A-D illustrate that the catalysts that calcined from $\mathrm{Ca}(\mathrm{OH})_{2}$ to $\mathrm{Fe}_{3} \mathrm{O}_{4}$ are better than that calcined from $\mathrm{CaCO}_{3}$ to $\mathrm{Fe}_{3} \mathrm{O}_{4}$, though $\mathrm{CaO}$ calcined from $\mathrm{CaCO}_{3}$ is better than that calcined from $\mathrm{Ca}(\mathrm{OH})_{2}$.

\subsubsection{Determination of recovery rate of catalysts}

Transesterification reactions were catalyzed by $\mathrm{CaO}$ and $\mathrm{Ca}(\mathrm{OH})_{2} 7$ respectively for $4 \mathrm{~h}$ under the conditions of methanol/oil mo1ar ratio of $15: 1$ and the catalyst dosage of $2 \%$ to oil at $70^{\circ} \mathrm{C}$. After $0.5 \mathrm{~h}$ quiescence in the $2200 \mathrm{G}$ magnetic field, the upper layer liquid was poured out and the remaining mixture was washed with isopropanol three times and then dried. According to the experiment results, the recovery rate of $\mathrm{CaO}$ is $55.95 \%$ while that of $\mathrm{Ca}(\mathrm{OH})_{2}$ is $91.45 \%$.

\subsubsection{Lifetime tests of catalysts}

Catalyzed by $\mathrm{Ca}(\mathrm{OH})_{2} 7$ and $\mathrm{CaO}$, respectively, transesterification reactions of Jatropha curcas oil were conducted under the same conditions. For every test, the experiment continued for $4 \mathrm{~h}$. For every catalyst, the tests repeated 10-times using fresh oil. The comparison results are shown in Fig. 3.

It can be observed in Fig. 3 that, after 5-times use, FAME yield is more than $90 \%$ for $\mathrm{Ca}(\mathrm{OH})_{2} 7$, and after 10 -times use, the FAME conversion still can reach more than $70 \%$. However, for $\mathrm{CaO}$, under the same conditions, the FAME conversion decreases to $22 \%$ after 5-times use, and after 8-times use, its catalytic activity is totally lost. Actually, after reaction, the $\mathrm{CaO}$ catalyst almost cannot be seen in the reactor since a large amount of $\mathrm{CaO}$ has been dissolved into the methanol or formed colloidal suspensions with methanol in the upper liquid and poured out with the reaction products.

B

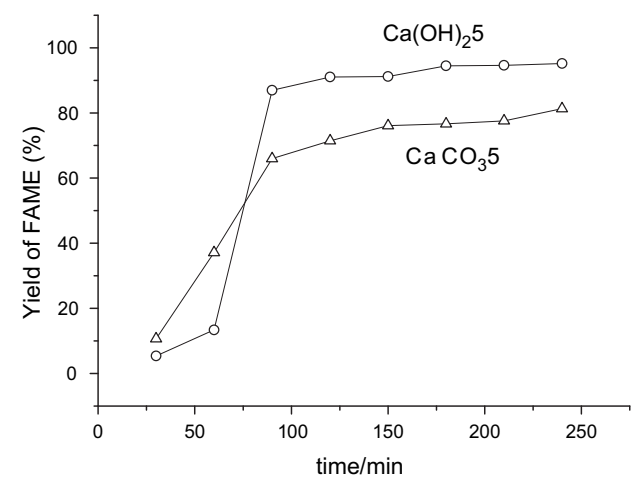

D

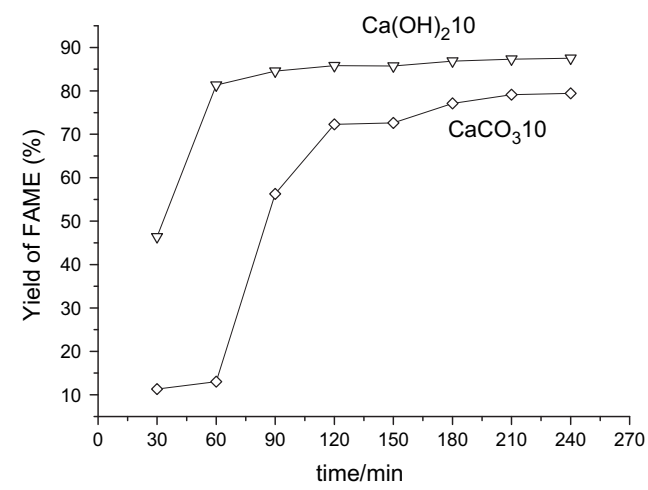

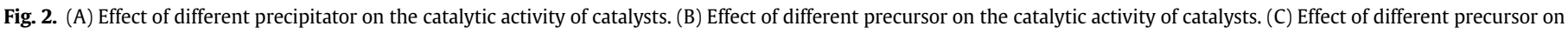
the catalytic activity of catalysts. (D) Effect of different precursor on the catalytic activity of catalysts. 


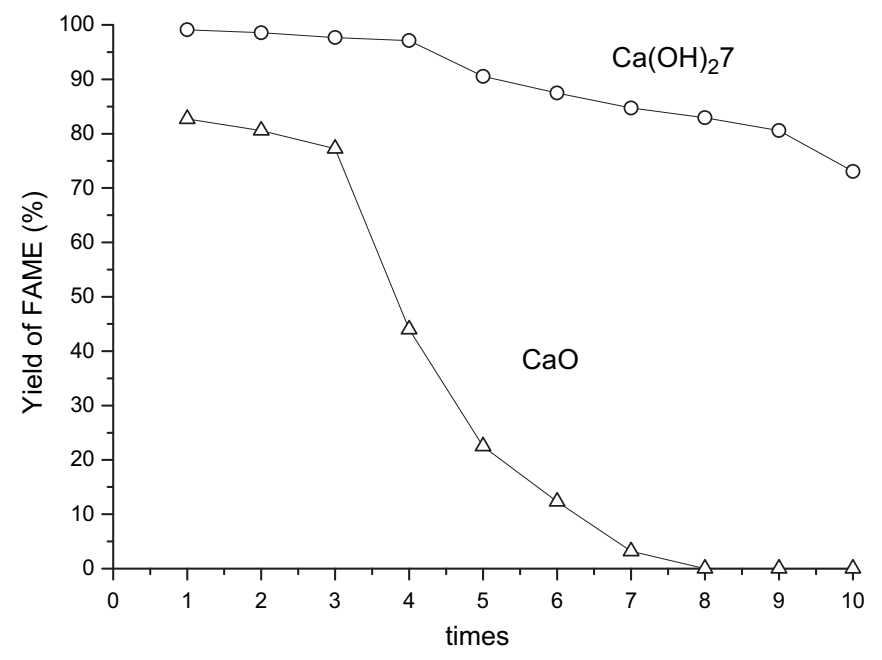

Fig. 3. Lifetime comparison of $\mathrm{Ca}(\mathrm{OH})_{2} 7$ and $\mathrm{CaO}$.

\subsection{Catalysts characterization}

\subsubsection{Differential thermogravimetric analysis of catalysts precursor}

$\mathrm{Ca}(\mathrm{OH})_{2}$ and $\mathrm{CaCO}_{3}$ can decompose to $\mathrm{CaO}$ by calcination. The catalysts prepared with 6 precursors: $\mathrm{Ca}(\mathrm{OH})_{2} 10, \mathrm{CaCO}_{3} 10$, $\mathrm{Ca}(\mathrm{OH})_{2} 7, \mathrm{CaCO}_{3} 7, \mathrm{Ca}(\mathrm{OH})_{2} 5$ and $\mathrm{CaCO}_{3} 5$ were investigated by the method of thermogravimetric analysis and Fig. 4 shows the result.

Based on Fig. 4, the mass of $\mathrm{Ca}(\mathrm{OH})_{2}$ supported catalyst reaches a plateau at $700{ }^{\circ} \mathrm{C}$, while the mass of $\mathrm{CaCO}_{3}$ supported catalyst comes steady at $780^{\circ} \mathrm{C}$. The ratio of decomposition of samples can be figured out by analyzing the loss of mass and the results are listed on Table 1 . Thereby, the calcination temperature was determined to be $800{ }^{\circ} \mathrm{C}$.

\subsubsection{Specific surface area}

Table 2 lists the specific surface areas of catalysts. The specific surface area of $\mathrm{CaO}$ is larger than that of any other kind of magnetic catalysts. This can be explained by that: during catalyst calcination, abundant pores will be formed when the generated gas escapes from the inner side of the catalyst; however, for magnetic core supported $\mathrm{Ca}(\mathrm{OH})_{2}$ or $\mathrm{CaCO}_{3}$ catalyst, the proportion of $\mathrm{CaO}$ is smaller, as well as the molecular weight of $\mathrm{Fe}_{3} \mathrm{O}_{4}$ being larger than

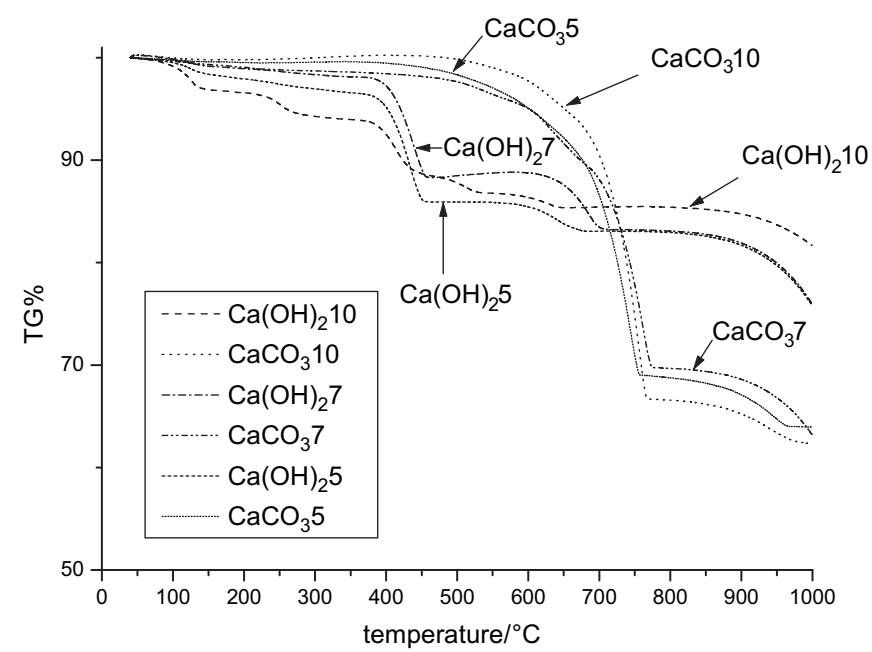

Fig. 4. The TG curves of catalysts prepared from different precursors.
Table 1

Ratio of decomposition of catalysts at $800{ }^{\circ} \mathrm{C}$.

\begin{tabular}{llr}
\hline Samples & TG\% at $800{ }^{\circ} \mathrm{C}$ & Decomposition ratio \% \\
\hline $\mathrm{Ca}(\mathrm{OH})_{2} 10$ & 85.40 & 78.80 \\
$\mathrm{CaCO} 10$ & 66.56 & 93.62 \\
$\mathrm{Ca}(\mathrm{OH})_{2} 7$ & 83.08 & 100.00 \\
$\mathrm{CaCO}_{3} 7$ & 69.68 & 91.74 \\
$\mathrm{Ca}(\mathrm{OH})_{2} 5$ & 82.93 & 100.00 \\
$\mathrm{CaCO}_{3} 5$ & 68.75 & 100.00 \\
\hline
\end{tabular}

that of $\mathrm{CaO}$. Among all of the magnetic catalysts, the specific surface area of $\mathrm{Ca}(\mathrm{OH})_{2} 7$ is the largest, which is possibly because that for an optimum proportion of $\mathrm{Ca}(\mathrm{OH})_{2}$ to $\mathrm{Fe}_{3} \mathrm{O}_{4}, \mathrm{CaO}$ distributes evenly on the magnetic core to form a larger surface area. When the proportion of $\mathrm{Ca}^{2+}$ to $\mathrm{Fe}_{3} \mathrm{O}_{4}$ is not great enough, such as $5: 1, \mathrm{CaO}$ cannot form such a lot of micro-pores; when the proportion is too great, such as 10:1, CaO may cluster together to cover some micropores. Hence, those are the reasons why the specific surface area of $\mathrm{Ca}(\mathrm{OH})_{2} 7$ is larger than that of any other magnetic catalysts.

\subsubsection{X-ray diffraction}

Fig. 5 shows the XRD pattern of the catalyst $\mathrm{Ca}(\mathrm{OH})_{2} 7$. There are two kinds of crystal in this catalyst, $\mathrm{Ca}_{2} \mathrm{Fe}_{2} \mathrm{O}_{5}$ and $\mathrm{CaO}$. After calcining the precursor of $\mathrm{Ca}(\mathrm{OH})_{2}-\mathrm{Fe}_{3} \mathrm{O}_{4}$ at $800{ }^{\circ} \mathrm{C}$ for $8 \mathrm{~h}$, $\mathrm{Ca}_{2} \mathrm{Fe}_{2} \mathrm{O}_{5}$, a kind of combined metal oxide crystalloid, is generated. This crystalloid maybe promotes the catalytic activity of magnetic catalyst.

In the pattern of XRD, the smaller the micro-crystalloid is, the larger the main peak area of interference function is, and the wider interference peak is. According to Scherer formula $D=0.89 \lambda / \beta \cos \theta$, the average particle size can be figured out. In this formula, $\lambda$ is the wavelength of X-ray; $\beta$ is FWHM of pure interference peak; $\theta$ is the half diffraction angle. Therefore, average particle size of main phase of crystalloid sample can be obtained with the calculation of the parameters of the three tallest peaks in the pattern. The average particle diameter is calculated to be $49.76 \mathrm{~nm}$.

\subsubsection{Magnetic strength analysis}

The magnetic strength of $\mathrm{Ca}(\mathrm{OH})_{2} 7$ was measured by VSM, and the result is exhibited in Fig. 6.

Fig. 6 suggests that, in the first place, it is proved that whether magnetic core $\mathrm{Fe}_{3} \mathrm{O}_{4}$, or the precursors of catalysts and the catalysts, they all display superparamagnetism because all the curves go through the original point. Secondly, the magnetic strength of precursor is smaller than that of pure $\mathrm{Fe}_{3} \mathrm{O}_{4}$, furthermore, the decreased proportion of magnetic strength is equal to the amount of $\mathrm{CaO}$ loaded on $\mathrm{Fe}_{3} \mathrm{O}_{4}$. The magnetic strength of magnetic catalysts is smaller than $1 \mathrm{eum} / \mathrm{g}$ possibly because some $\mathrm{Fe}_{3} \mathrm{O}_{4}$ is oxidized to $\alpha-\mathrm{Fe}_{2} \mathrm{O}_{3}$ during the calcination process.

Because of the magnet, catalyst $\mathrm{Ca}(\mathrm{OH})_{2} 7$ can be separated from reaction system rapidly by forcing magnetic field and absorbed to the bottom of lower layer of glycerin. That is the reason why the recovery rate of magnetic catalysts can reach up as high as $91.45 \%$.

Table 2

The specific surface area of catalysts.

\begin{tabular}{ll}
\hline Catalysts & $\begin{array}{l}\text { The specific surface area } \\
\left(\mathrm{m}^{2} / \mathrm{g}\right)\end{array}$ \\
\hline $\mathrm{Ca}(\mathrm{OH})_{2} 10$ & 1.74 \\
$\mathrm{CaCO} 10$ & 1.18 \\
$\mathrm{Ca}(\mathrm{OH})_{2} 7$ & 3.72 \\
$\mathrm{CaCO}_{3} 7$ & 1.96 \\
$\mathrm{Ca}(\mathrm{OH})_{2} 5$ & 1.96 \\
$\mathrm{CaCO} 5$ & 1.36 \\
$\mathrm{CaO}\left(\right.$ from $\mathrm{Ca}\left(\mathrm{OH}_{2}\right)$ & 5.90 \\
$\mathrm{CaO}\left(\right.$ from $\left.\mathrm{CaCO}_{3}\right)$ & 3.94 \\
\hline
\end{tabular}




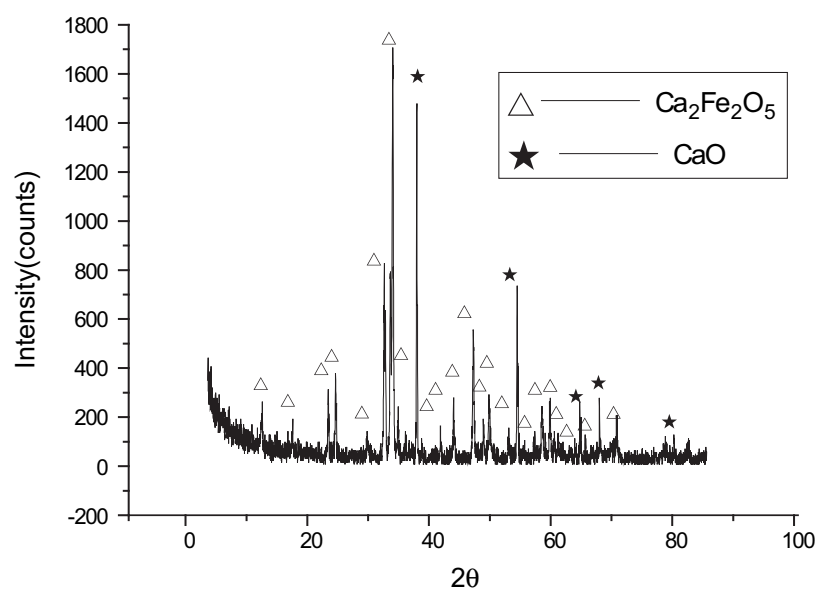

Fig. 5. XRD pattern of $\mathrm{Ca}(\mathrm{OH})_{2} 7$.

3.2.5. Scanning electronic microscope and transmission electron microscopy

Fig. 7A, the transmission electron microscopy photograph, reveals that the $\mathrm{Fe}_{3} \mathrm{O}_{4}$ appears as tiny balls whose diameter is $10 \mathrm{~nm}$. Nanometer $\mathrm{Fe}_{3} \mathrm{O}_{4}$ have superparamagnetism which means that the matter with this nature displays magnet in magnetic field,
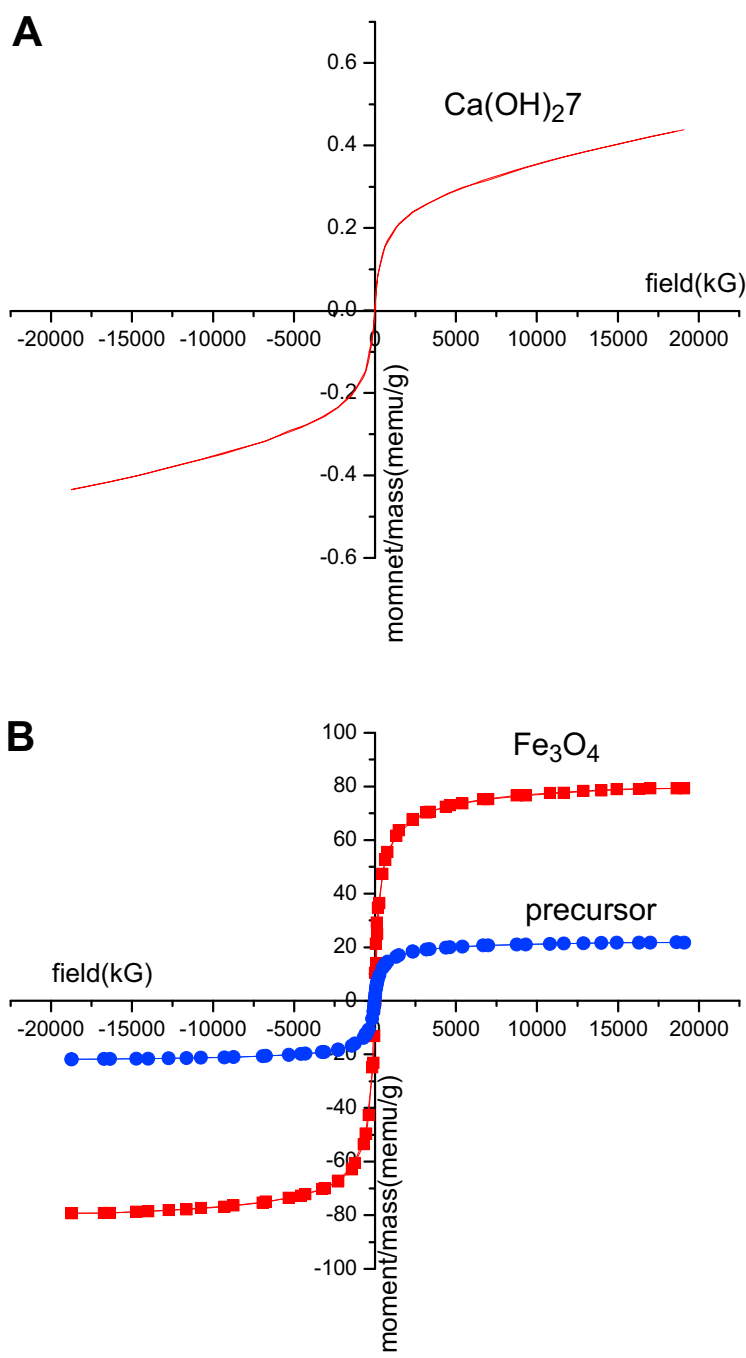

Fig. 6. (A) $M-H$ curves of super paramagnet of catalysts. (B) $M-H$ curves of super paramagnet of catalysts.
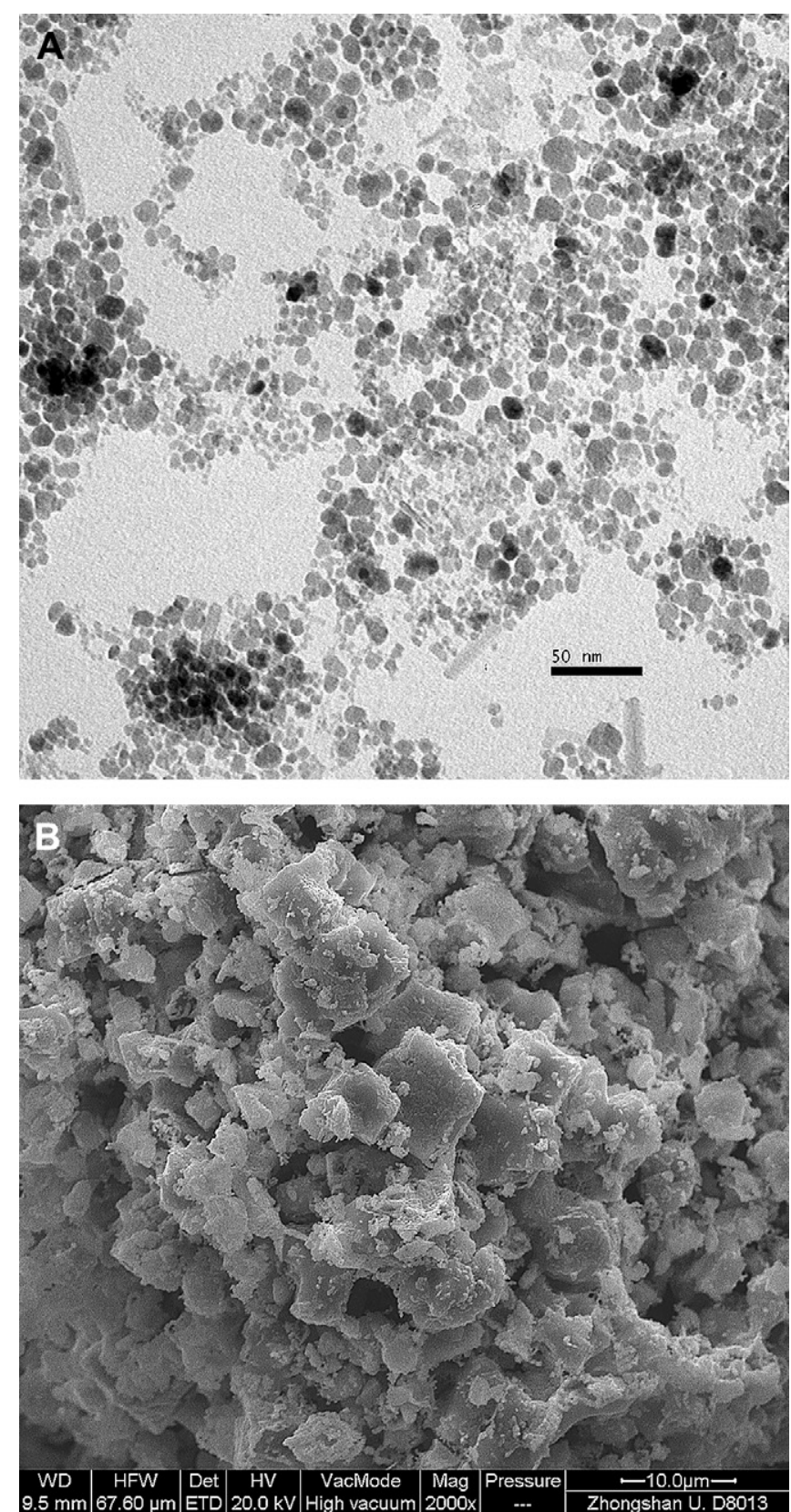

Fig. 7. (A) TEM photo of $\mathrm{Fe}_{3} \mathrm{O}_{4}$. (B) $\mathrm{SEM}$ photo of $\mathrm{CaO}-\mathrm{Fe}_{3} \mathrm{O}_{4}$.

but non-magnetic in the non-magnetic surrounding. When $\mathrm{CaO}$ is loaded on the magnetic core, it still has this feature. This nature makes catalysts disperse well in the reactant system and be separated easily by the external magnetic field.

Fig. 7B, the Scanning electronic microscope photograph of $\mathrm{Ca}(\mathrm{OH})_{2} 7$, demonstrates that the main substance $\mathrm{Ca}_{2} \mathrm{Fe}_{2} \mathrm{O}_{5}$ is cuboid and some of pure $\mathrm{CaO}$ attaches on the surface of the cuboid. It suggests that when $\mathrm{Ca}^{2+}: \mathrm{Fe}_{3} \mathrm{O}_{4}=10$, there is more pure $\mathrm{CaO}$ on the surface which prevents the connection between the catalysts and reagents; when $\mathrm{Ca}^{2+}: \mathrm{Fe}_{3} \mathrm{O}_{4}=5$, there are less active crystalloids formed. Maybe this is another reason why $\mathrm{Ca}(\mathrm{OH})_{2} 7$ is most active for transesterification reaction.

\section{Conclusions}

Nanometer magnetic solid base catalysts can be prepared by loading $\mathrm{CaO}$ on $\mathrm{Fe}_{3} \mathrm{O}_{4}$ with $\mathrm{Na}_{2} \mathrm{CO}_{3}$ or $\mathrm{NaOH}$ as precipitator. 
$\mathrm{Ca}_{2} \mathrm{Fe}_{2} \mathrm{O}_{5}$, a new kind of crystalloid with high catalytic activity, is formed by calcining the precursors. This achieves assembly of magnet and catalytic activity.

The catalytic activity of catalysts which are obtained by calcining $\mathrm{Ca}(\mathrm{OH})_{2}-\mathrm{Fe}_{3} \mathrm{O}_{4}$ is better than that by calcining $\mathrm{CaCO}_{3}-\mathrm{Fe}_{3} \mathrm{O}_{4}$. Furthermore, $\mathrm{Ca}^{2+}: \mathrm{Fe}_{3} \mathrm{O}_{4}=7$ is the optimum proportion for catalytic activity. The conversion rate of transesterification reaction catalyzed by $\mathrm{Ca}(\mathrm{OH})_{2} 7$ can reach $95 \%$ in $80 \mathrm{~min}$, and to $99 \%$ in $4 \mathrm{~h}$.

The recovery rate of $\mathrm{Ca}(\mathrm{OH})_{2} 7$ after reaction can reach up to $91.45 \%$, which is much higher than $55.95 \%$, the recovery rate of $\mathrm{CaO}$. Moreover, the conversion rate of transesterification reaction is more than $90 \%$ when the reaction is catalyzed by 5 -times used Ca $(\mathrm{OH})_{2} 7$, and after 10 -times use, it is still more than $70 \%$.

\section{Acknowledgement}

The financial fund received from High Technology R\&D Program (863 project) (2007AA05Z412) and 2006 Guangdong Province Key Technology (200649851301) is much appreciated.

\section{References}

[1] Carraretto C, Macor A, Mirandola A, Stoppato A. Tonon S. Biodiesel as alternative fuel: experimental analysis and energetic evaluations. Energy 2004;29:2195-211.

[2] Graboski MS, McCormick RL. Combustion of fat and vegetable oil derived fuels in diesel engines. Prog Energy Combust Sci 1998;24:125-64.

[3] Freedman B, Pryde EH, Mounts TL. Variables affecting the yields of fatty esters from transesterified vegetable oils. J Am Oil Chem Soc 1984;61:38-43.

[4] Mazzocchia C, Modica G, Nannicini R, Kaddouri A. Fatty acid methyl esters synthesis from triglycerides over heterogeneous catalysts in the presence of microwaves. C R Chim 2004;6-7:601-5.

[5] Yang ZQ Xie WL. Soybean oil transesterification over zinc oxide modified with alkali earth metals. Fuel Process Technol 2007;88:631-8.

[6] Leclercq E, Finiels A, Moreau C. Transesterification of rapeseed oil in the presence of basic zeolites and related solid catalysts. J Am Oil Chem Soc 2001;78:1161-5.
[7] Di Serio M, Ledda M, Cozzolino M, Minutillo G, Tesser R, Santacesaria E. Transesterification of soybean oil to biodiesel by using heterogeneous basic catalysts. Ind Eng Chem Res 2006;45:3009-14.

[8] Oku T, Nonoguchi M, Moriguchi T. Method of production of fatty acid alky esters and/or glycerine and fatty acid alkyl ester-containing composition. PCT Application No WO/2005/021697; 2005.10.03.

[9] Corma A, Hamid SBA, Iborra S, Velty A. Lewis and Brönsted basic active sites on solid catalysts and their role in the synthesis of monoglycerides. J Catal 2005;234:340-7.

[10] Shumaker JL, Crofcheck C, Tackett SA, Santillan-Jimenez E, Crocker M. Biodiesel production from soybean oil using calcined $\mathrm{Li}-\mathrm{Al}$ layered double hydroxide catalysts. Catal Lett 2007;115:56-61.

[11] Ebiura T, Echizen T, Ishikawa A, Murai K, Baba T. Selective transesterification of triolein with methanol to methyl oleate and glycerol using alumina loaded with alkali metal salt as a solid-base catalyst. Appl Cat A 2005;283:111-6.

[12] Kim HJ, Kang BS, Kim MJ, Park YM, Kim DK, Lee JS, et al. Transesterification of vegetable oil to biodiesel using heterogeneous base catalyst. Catal Today 2004;93-95:315-20.

[13] Xie WL, Peng H, Chen LG. Transesterification of soybean oil catalyzed by potassium loaded on alumina as a solid-base catalyst. Appl Catal A 2006;300:67-74.

[14] Xie WL, Huang XM. Synthesis of biodiesel from soybean oil using heterogeneous KF/ZnO Catalyst. Cat Lett 2006;107:53-9.

[15] Lotero E, Goodwin Jr JG, Bruce DA, Suwannakarn K, Liu Y, Lopez DE. Catalysis 2006;19:41-84.

[16] Liu XJ, He HY, Wang YJ, Zhu SL. Transesterification of soybean oil with methanol to biodiesel using calcium oxide as a solid base catalyst. Pet Proc Petrochem 2006;37:39-43.

[17] Albuquerque Monica CG, Jimenez-Urbistondo Inmaculada, SantamariaGonzalez Jose. $\mathrm{CaO}$ supported on mesoporous silicas as basic catalysts for transesterification reactions. Appl Catal A 2008;334:35-43.

[18] Arzamendi G, Arguinarena E, Campo I, Zabala S, Gandia LM. Alkaline and alkaline-earth metals compounds as catalysts for the methanolysis of sunflower oil. Catal Today 2008;133-135:305-13.

[19] Kouzu Masato, Kasuno Takekazu, Tajika Masahiko, Sugimoto Yoshikazu, Yamanaka Shinya, Hidaka Jusuke. Calcium oxide as a solid base catalyst for transesterification of soybean oil and its application to biodiesel production. Fuel 2008;87:2798-806.

[20] Reddy C, Reddy V, Oshel R, Verkade JG. Room-temperature conversion of soybean oil and poultry fat to biodiesel catalyzed by nanocrystalline calcium oxides. Energy Fuels 2006;20:1310-4.

[21] Yan SL, Lu HF, Jiang LH, Liang B. Solid base catalysts for transesterification of oil with methanol to produce biodiesel. J Chem Indus Eng (China) 2007;58:2506-12. 